\title{
Influence of the Organic Layer Thickness in (Metal-Assisted) Secondary Ion Mass Spectrometry Using $\mathrm{Ga}^{+}$and $\mathrm{C}_{60}^{+}$Projectiles
}

\author{
Nimer Wehbe, Taoufiq Mouhib, Aneesh Prabhakaran, Patrick Bertrand, \\ and Arnaud Delcorte \\ Unité de Physico-Chimie et de Physique des Matériaux, Université catholique de Louvain, Louvain la Neuve, \\ Belgium
}

\begin{abstract}
This article investigates the influence of the organic film thickness on the characteristic and molecular ion yields of polystyrene (PS), in combination with two different substrates (Si, Au) or gold condensation (MetA-SIMS), and for atomic $\left(\mathrm{Ga}^{+}\right)$and polyatomic $\left(\mathrm{C}_{60}^{+}\right)$projectile bombardment. PS oligomer $(m / z \sim 2000 \mathrm{Da})$ layers were prepared with various thicknesses ranging from 1 up to $45 \mathrm{~nm}$ on both substrates. Pristine samples on Si were also metallized by evaporating gold with three different thicknesses $(0.5,2$, and $6 \mathrm{~nm})$. Secondary ion mass spectrometry was performed using $12 \mathrm{keV}$ atomic $\mathrm{Ga}^{+}$and $\mathrm{C}_{60}^{+}$projectiles. The results show that upon $\mathrm{Ga}^{+}$bombardment, the yield of the fingerprint fragment $\mathrm{C}_{7} \mathrm{H}_{7}^{+}$increases as the PS coverage increases and reaches its maximum for a thickness that corresponds to a complete monolayer $(\sim 3.5 \mathrm{~nm})$. Beyond the maximum, the yields decrease strongly and become constant for layers thicker than $12 \mathrm{~nm}$. In contrast, upon $\mathrm{C}_{60}^{+}$bombardment, the $\mathrm{C}_{7} \mathrm{H}_{7}^{+}$yields increase up to the monolayer coverage and they remain constant for higher thicknesses. A strong yield enhancement is confirmed upon $\mathrm{Ga}^{+}$analysis of gold-metallized layers but yields decrease continuously with the gold coverage for $\mathrm{C}_{60}^{+}$bombardment. Upon $\mathrm{Ga}^{+}$bombardment, the maximum PS fingerprint ion yields are obtained using a monolayer spin-coated on gold, whereas for $\mathrm{C}_{60}^{+}$, the best results are obtained with at least one monolayer, irrespective of the substrate and without any other treatment. The different behaviors are tentatively explained by arguments involving the different energy deposition mechanisms of both projectiles. (J Am Soc Mass Spectrom 2009, 20, 2294-2303) @ 2009 American Society for Mass Spectrometry
\end{abstract}

$\mathrm{A}$ mong the techniques of surface characterization, time-of-flight secondary ion mass spectrometry (TOF-SIMS) is a method of choice, sensitive to the outermost layer of the solid. It provides valuable molecular information with low detection limits [1]. At low primary ion dose (static SIMS) [2], the probability that two projectiles hit the same impact area is negligible, so that a "non destructive" mode can be easily achieved. Because of the detailed molecular information found in the mass spectra, TOF-SIMS has been extensively applied to study polymer films [3, 4] and biological molecules [5, 6].

For thin layers, the nature of the inorganic substrate is a major factor influencing the yield defined as the number of detected ion per incident projectile. Specific substrates such as noble metals strongly enhance the characteristic secondary ions yields upon atomic projectile bombardment $[4,7,8]$. Moreover, the signal intensities from a given compound are affected by the surface coverage but they are not always proportional to the amount of the compound available at the surface

Address reprint requests to Dr. N. Wehbe, Research Centre in Physics of Matter and Radiation (PMR), University of Namur (FUNDP), Rue de Bruxelles 61, B-5000 Namur, Belgium. E-mail: Nimer.wehbe@fundp.ac.be
[6, 9-13]. The characterization of polystyrene oligomers (PS) on etched silver by $10 \mathrm{keV}$ monoatomic $\mathrm{Ar}^{+}$ projectiles showed that the maximum yields were obtained when PS was prepared as a monolayer [11]. Other experiments performed with PMMA and PVC polymers led to similar conclusions [12]. The common factors for the aforementioned experiments were the use of coatings on specific substrates, in combination with an atomic projectile for analysis. In such case, characteristic ion yield enhancement is generally observed as long as the substrate signals are apparent.

Upon atomic projectile bombardment, the ability of noble metals to enhance the molecular yields remains valid if these metals are evaporated onto the organic layer instead of using them as substrate. The enhancement factor for organic molecules can reach two orders of magnitude and more in some instances [14]. This specific sample preparation protocol, called metal assisted-SIMS (MetA-SIMS), was successfully used for signal enhancement with various materials such as polymers [15, 16], organic molecules [17], and, in particular, for a better sensitivity in high-resolution surface imaging [18].

On the other hand, polyatomic projectiles constitute a very efficient solution to overcome the issue of 
low molecular secondary ion yields. Compared with atomic projectile, clusters such as $\mathrm{C}_{60}^{+}, \mathrm{Bi}_{n}^{+}$, and $\mathrm{Au}_{n}^{+}$ have shown their capability to improve the characteristic yields from organic $[19,20]$ samples by orders of magnitude. The combination of polyatomic projectiles with specific substrates for thin film analysis has not been systematically studied yet. However, existing reports indicate that the yield enhancement seems to be much more limited than for bulk organics [21, 22]. In a similar manner, the efficiency of MetA-SIMS could only be proved in the case of atomic projectiles $[7,23]$.

The main goal of this study is to investigate the influence of the organic layer thickness on the ion yields under polyatomic $\left(\mathrm{C}_{60}^{+}\right)$projectile bombardment. The thickness effect on the ion yields will be assessed for two different substrates ( $\mathrm{Si}$ and $\mathrm{Au}$ ) and for gold condensation (MetA-SIMS). The results will be systematically compared with those obtained under monatomic $\mathrm{Ga}^{+}$bombardment. The chosen samples are films of low molecular weight polystyrene oligomers (PS: $\mathrm{m} / \mathrm{z}$ $\sim 2000 \mathrm{Da})$.

\section{Experimental}

\section{Sample}

Polystyrene oligomers were purchased from SigmaAldrich Co. with an average molecular weight $\left(\mathrm{M}_{\mathrm{w}}\right)$ of $2000 \mathrm{Da}$ and a polydispersity index of about 1.06 . The end groups of the chosen polystyrene are $\mathrm{H}$ and $\mathrm{C}_{4} \mathrm{H}_{9}$ and, thus, the chemical formula is $\mathrm{H}-\left(\mathrm{C}_{8} \mathrm{H}_{8}\right)_{\mathrm{n}}-\mathrm{C}_{4} \mathrm{H}_{9}$. The $\mathrm{M}_{\mathrm{w}}$ value could be verified under $\mathrm{C}_{60}^{+}$projectile bombardment. Pristine PS films with various thicknesses were prepared by serial dilution of a $20 \mathrm{mg} / \mathrm{mL}$ solution of the polymer in toluene, down to $0.1 \mathrm{mg} / \mathrm{mL}$. Solutions were subsequently spin-coated on clean silicon wafers by letting a droplet of each solution evaporate at $5000 \mathrm{rpm}$ during $80 \mathrm{~s}$. Before spin-coating, the silicon wafers were cleaned with acetone and isopropanol. The thicknesses of the different films were in the range $\sim 1$ up to $\sim 45 \mathrm{~nm}$, as measured by ellipsometry Table 1. The error on the thickness measurements was less than $5 \%$ for each substrate. The metallized samples were obtained by evaporation of gold $(0.5 ; 2$ and $6 \mathrm{~nm}$ equivalent thickness) onto the pristine samples. The

Table 1. Ellipsometry measurements carried out on PS spin-coated onto silicon and gold substrates with increasing concentrations $(0.1 \text { to } 20 \mathrm{mg} / \mathrm{mL})^{*}$

\begin{tabular}{ccc}
\hline & \multicolumn{2}{c}{ Thickness $(\mathrm{nm})$} \\
\cline { 2 - 3 } Concentration $\mathrm{mg} / \mathrm{mL}$ & $\mathrm{PS} / \mathrm{Si}$ & $\mathrm{PS} / \mathrm{Au}$ \\
\hline \hline 0.1 & 1.5 & 1 \\
1 & 3.8 & 3.1 \\
5 & 12.6 & 12.1 \\
20 & 45.4 & 45.5 \\
\hline
\end{tabular}

* The layer thicknesses are given in $\mathrm{nm}$. The error on the thickness measurements is less than $5 \%$ for each sample. third set of samples was prepared by evaporating $50 \mathrm{~nm}$ of gold metal directly on the Si wafers to obtain gold substrates. PS solutions were subsequently spin-coated on these gold substrates. Spin-coating was performed using KARL SUSS spin coater. Gold deposition was carried out using electron beam evaporation technique in a BOC Edwards AUTO306 evaporator (Crawley, UK). The metallization chamber was first pumped down to $4-8 \times 10^{-6}$ mbar. Then the beam current was gradually increased up to about $30 \mathrm{~mA}$, which allows the gold to evaporate at the rate of about $1 \mathrm{~nm} / \mathrm{s}$. The thickness of the gold deposited was measured using a quartz crystal microbalance, which operates by monitoring the frequency of a quartz crystal on which the evaporated gold is deposited.

\section{Secondary Ion Mass Spectrometry}

The secondary ion mass analyses were performed using two different projectile sources interfaced with a PHIEVANS time-of-flight SIMS (TRIFT 1) and allowing us to reach $12 \mathrm{keV} \mathrm{Ga}{ }^{+}$and $\mathrm{C}_{60}^{+}$impact energies in the positive analysis polarity. The experimental setup has been described in detail elsewhere [24]. The ${ }^{69} \mathrm{Ga}^{+}$beam was obtained from a FEI 83-2 liquid metal ion source ( $~ 1 \mathrm{nA}$ dc current; $5 \mathrm{kHz}$ frequency; $22 \mathrm{~ns}$ pulse width bunched down to $1 \mathrm{~ns}$ ). The $\mathrm{C}_{60}^{+}$measurements were conducted using a primary ion beam system (IOG-C6020) from Ionoptika Ltd. ( $\sim 160 \mathrm{pA}$ dc current and $\sim 20 \mathrm{~ns}$ pulse width). To maximize the measured intensities, the secondary ions were postaccelerated by a high voltage $(7 \mathrm{kV})$ in front of the detector. This post-acceleration increases the detection efficiency of the emitted ions reaching the front of the microchannel plate detector (MCP) [25]. The TOF SIMS mass spectra were obtained by collecting the secondary ion signal in the mass range $0<m / z<5000$ for the $180 \mathrm{~s}$ bombardment of a $120 \times$ $120 \mu \mathrm{m}^{2}$ sample area. The chosen parameters correspond to a projectile fluence lower or close to $10^{11}$ ions $/ \mathrm{cm}^{2}$ for all used primary ion species, ensuring static bombardment conditions. Each experimental point of the figures corresponds to the average value calculated for three different measurements on the same sample.

\section{Results and Discussion}

First, the effects and combined effects of projectile nature and gold evaporation will be presented as a function of the organic layer thickness for PS spin-coated on $\mathrm{Si}$ substrates. We will focus, in particular, on the secondary ion yields of $\mathrm{C}_{7} \mathrm{H}_{7}^{+}$fragment, gold cationized molecular ion $(\mathrm{M}+\mathrm{Au})^{+}$, and gold ions ejected as $\mathrm{Au}_{n}^{+}$ $(1 \leq n \leq 13)$. The same systematic study was conducted using gold substrates. These results will be presented and compared with those obtained for Si substrate in the last part of the article. 


\section{Mass Spectra of PS Monolayers}

The $12 \mathrm{keV} \mathrm{Ga}^{+}$-induced mass spectra of a series of thin PS samples are shown in Figure 1. The concentration of the spin-coated PS solution was $1 \mathrm{mg} / \mathrm{mL}$ and ellipsometric measurements indicate that the layer thickness is in the range 3-4 $\mathrm{nm}$ for those samples (Table 1). The thickness values indicate that for $1 \mathrm{mg} / \mathrm{mL}$, PS forms a monolayer coverage [11, 12]. The mass spectra represent the intensity variation of the Au-cationized molecular ion, $(\mathrm{M}+\mathrm{Au})^{+}$, for PS spin-coated on $\mathrm{Si}$ and

(a)

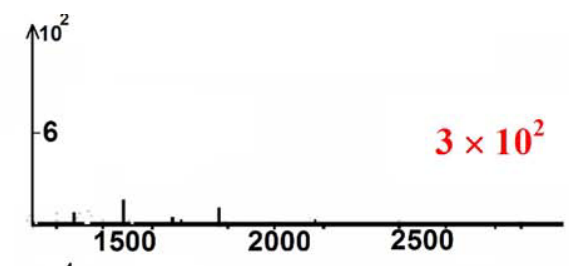

(b)
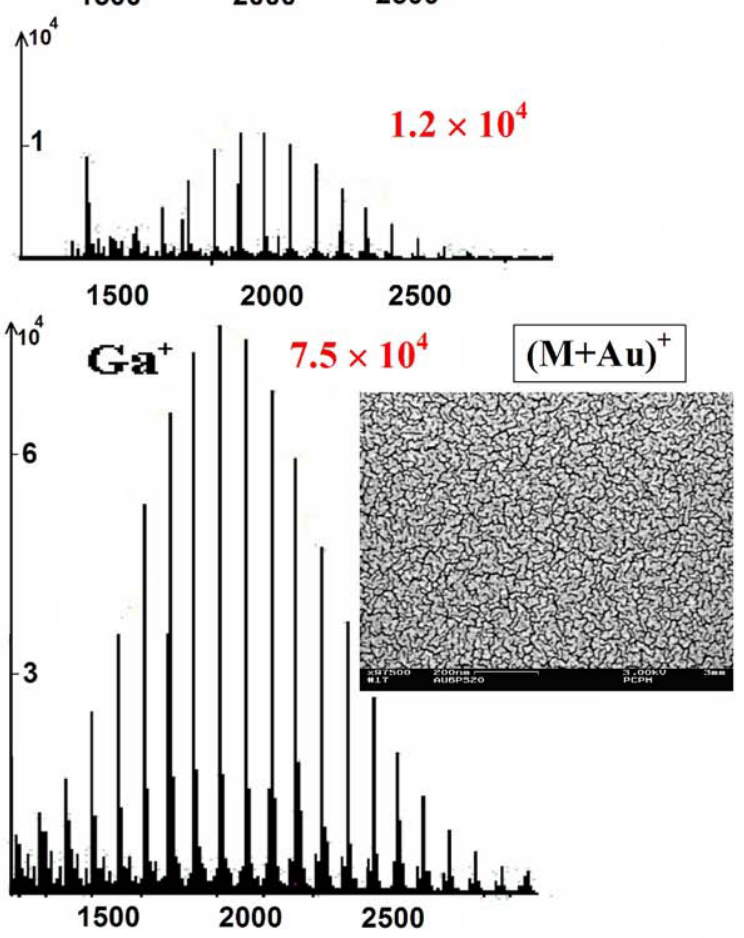

(c)

(d)

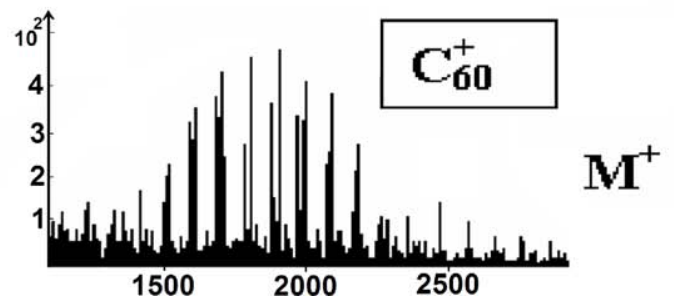

Figure 1. Mass spectra of PS spin-coated as $1 \mathrm{mg} / \mathrm{mL}$ onto Si (a), (b), and $\mathrm{Au}$ (c) substrates, recorded under $\mathrm{Ga}^{+}$bombardment. The spectra exposes the intensity variations of $(\mathrm{M}+\mathrm{Au})^{+}$for $(\mathbf{a})$ PS metallized with $0.5 \mathrm{~nm} \mathrm{Au}$, (b) PS metallized with $6 \mathrm{~nm} \mathrm{Au}$, and (c) PS spin-coated on gold substrate. The intensity values written near each spectrum correspond to the highest peak. The spectrum (d) shows the PS molecular ions $\mathrm{M}^{+}$detected from the untreated PS sample spin-coated as $1 \mathrm{mg} / \mathrm{mL}$ onto Si using $\mathrm{C}_{60}^{+}$primary ions. The inset image illustrates a scanning electron microscopy (SEM) image recorded for PS on which $6 \mathrm{~nm}$ of gold was evaporated. metallized with $0.5 \mathrm{~nm} \mathrm{Au} \mathrm{(a),} \mathrm{PS} \mathrm{metallized} \mathrm{with} 6 \mathrm{~nm}$ $\mathrm{Au}(\mathrm{b})$, and PS spin coated on Au substrate (c). The intensity value written near each distribution corresponds to the highest peak. For comparison, the PS molecular ions detected for $\mathrm{C}_{60}^{+}$bombardment of the pristine sample are shown in the spectrum (d).

Upon $\mathrm{Ga}^{+}$bombardment, PS molecular ions are not detected for PS spin-coated on Si substrates without any treatment (pristine), whereas these ions appear clearly when the $\mathrm{C}_{60}^{+}$ion source is used (Figure 1d). The parent-like ions $(\mathrm{M}+\mathrm{Au})^{+}$start appearing with $0.5 \mathrm{~nm}$ of gold and then increase drastically with the amount of deposited gold. The yield value is multiplied by 40 if we evaporate $6 \mathrm{~nm}$ of gold onto the PS monolayer instead of $0.5 \mathrm{~nm}$. The yield increases more if the PS monolayer is spin-coated on gold substrate rather than metallize it by $6 \mathrm{~nm} \mathrm{Au}$. The inset image illustrates a scanning electron microscopy (SEM) image recorded for PS on which $6 \mathrm{~nm}$ of gold was evaporated. This image shows that the $\mathrm{Au}$ atoms coalesce to form droplet-like islands on the surface. From the experimental mass spectra, one can calculate the secondary ion yields. The evolutions of the characteristic fingerprint fragment $\mathrm{C}_{7} \mathrm{H}_{7}^{+}$and the adduct $(\mathrm{M}+\mathrm{Au})^{+}$ion yields as a function of the organic layer thickness are discussed next.

\section{Yield Variations as a Function of the PS Layer Thickness}

Ellipsometry measurements carried out on spin-coated PS samples show that the layer thickness increases as the PS concentration increases (Table 1). Moreover, from $1 \mathrm{mg} / \mathrm{mL}$, the correlation between concentrations and thicknesses is almost linear. Therefore, the concentration scale can be easily transformed into a thickness scale. Table 1 also shows that the measured thicknesses are very close for PS spin-coated on silicon and gold substrates, except for the lowest PS concentrations, which might be due to the limitations of the ellipsometric measurements for such very thin coverage.

The $\mathrm{C}_{7} \mathrm{H}_{7}^{+}$secondary ion yields are presented as a function of the PS concentration in Figure 2, for PS spin-coated onto $\mathrm{Si}$ substrates and measured under $\mathrm{Ga}^{+}$ (Figure 2a) and $\mathrm{C}_{60}^{+}$(Figure $2 \mathrm{~b}$ ) bombardment. The yields corresponding to pristine and Au-metallized PS coatings are reported on the same graphs. The $\mathrm{C}_{7} \mathrm{H}_{7}^{+}$ values for the pristine sample of Figure 2a were multiplied by 5 to better distinguish the corresponding curve. The same presentation will be used in Figure 3 for gold adduct ions. Upon $\mathrm{Ga}^{+}$bombardment, the $\mathrm{C}_{7} \mathrm{H}_{7}^{+}$yield measured on pristine samples increases as the PS concentration increases and reaches its maximum for 1 $\mathrm{mg} / \mathrm{mL}$ ( $\sim 3.5 \mathrm{~nm}$ layer thickness). As was established before, this thickness can be attributed to a full PS monolayer. Beyond the maximum, the yield decreases strongly and becomes almost constant between 5 and 20 $\mathrm{mg} / \mathrm{mL}$. The $\mathrm{C}_{7} \mathrm{H}_{7}^{+}$yield is five times higher if PS is spin-coated as a monolayer rather than a thick layer. 

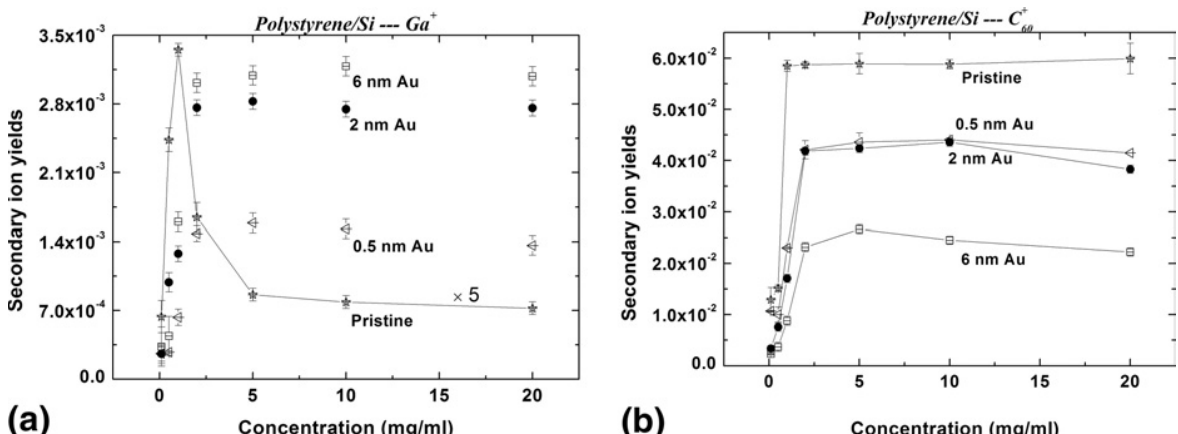

Figure 2. Secondary ion yields for $\mathrm{C}_{7} \mathrm{H}_{7}^{+}$as a function of the concentrations of PS spin-coated onto Si substrates. The results are depicted for untreated PS and for PS layers on which the gold is evaporated with three different thicknesses $(0.5,2$, and $6 \mathrm{~nm})$. The results are displayed for $(\mathbf{a}) \mathrm{Ga}^{+}$ and (b) $\mathrm{C}_{60}^{+}$primary ions. In Fig $2 \mathrm{a}$, the yield values of $\mathrm{C}_{7} \mathrm{H}_{7}^{+}$depicted for the pristine sample were multiplied by 5 . The lines are to guide the eyes.

After evaporation of Au onto the samples, two differences can be clearly noticed. First, for each metallization condition, the yields increase as the PS concentration increases up to $2 \mathrm{mg} / \mathrm{mL}$ value, beyond which they remain constant. For thick samples, they are consistently more than one order of magnitude higher than those obtained for pristine samples. Second, the yields increase drastically when the thickness of the evaporated $\mathrm{Au}$ rises from 0.5 to $2 \mathrm{~nm}$. They continue increasing up to $6 \mathrm{~nm}$, but with a lower rate. Under $\mathrm{C}_{60}^{+}$ bombardment (Figure $2 b$ ), the $\mathrm{C}_{7} \mathrm{H}_{7}^{+}$yield for pristine samples increases up to $1 \mathrm{mg} / \mathrm{mL}$ and, in contrast to $\mathrm{Ga}^{+}$, it remains constant for higher PS concentrations. For thick layers, the yield values are more than two orders of magnitude higher that those measured upon $\mathrm{Ga}^{+}$bombardment. Another striking difference with the $\mathrm{Ga}^{+}$results, already observed in a previous study of triacontane samples [7], occurs after Au evaporation. With $\mathrm{C}_{60}^{+}$projectiles, metallization leads to a yield decrease even after evaporation of $0.5 \mathrm{~nm}$ Au. The higher the Au amount deposited on the sample, the lower the yield. Note, however, that the yields after $\mathrm{Au}$ evaporation are still higher than those obtained upon $\mathrm{Ga}^{+}$measurements ( $\sim 1$ order of magnitude).

Among the benefits of using Au for metallization is the detection of the cationized fragments and molecular ions. The secondary ion yields for Au cationized molecular $(\mathrm{M}+\mathrm{Au})^{+}$ions as a function of the PS concentration are displayed in Figure 3 for $\mathrm{Ga}^{+}$(a) and $\mathrm{C}_{60}^{+}(\mathrm{b})$ projectiles. The behavior of this ion is similar to that observed for the $\mathrm{C}_{7} \mathrm{H}_{7}^{+}$fragment. Indeed, for a given evaporated $\mathrm{Au}$ thickness, the yields increase up to $\sim 2$ $\mathrm{mg} / \mathrm{mL}$ and remain almost constant for higher PS concentrations. For $\mathrm{Ga}^{+}$bombardment, the yields increase as the amount of the evaporated $\mathrm{Au}$ increase while for $\mathrm{C}_{60}^{+}$bombardment, a maximum is already reached for $0.5 \mathrm{~nm} \mathrm{Au}$ and the yields decrease for larger gold thicknesses.

By comparing the yield values obtained for the adduct ion to those measured for the fragment in (Figure 2a), we conclude that the $\mathrm{C}_{7} \mathrm{H}_{7}^{+}$yields are between 7 and 10 times higher than those calculated for the adduct ion under $\mathrm{Ga}^{+}$bombardment. For $\mathrm{C}_{60}^{+}$projectiles, this difference is much larger, since it always reaches at least two orders of magnitude. Taking a global look at the yield comparisons between both projectiles we observe that, for the molecular adduct ions $(\mathrm{M}+\mathrm{Au})^{+}, \mathrm{C}_{60}^{+}$only provides higher yields than $\mathrm{Ga}^{+}$with $0.5 \mathrm{~nm}$ of $\mathrm{Au}$. For larger Au thicknesses, the absolute yields become higher with $\mathrm{Ga}^{+}$. They are multiplied by factors of $\sim 2$ and $\sim 6$ after evaporation of 2 and $6 \mathrm{~nm} \mathrm{Au}$, respectively, if $\mathrm{Ga}^{+}$is used as projectile
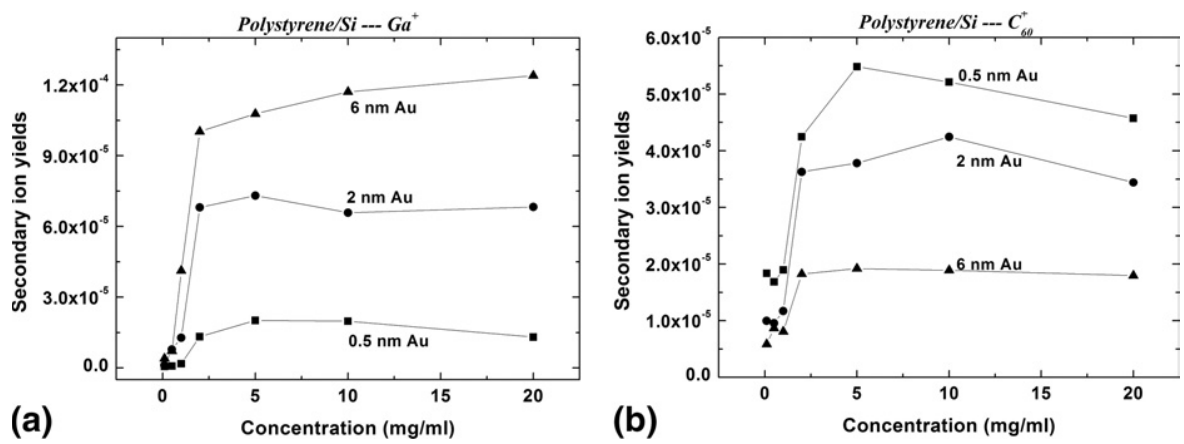

Figure 3. Secondary ion yields for $\mathrm{Au}$ cationized molecular ions $(\mathrm{M}+\mathrm{Au})^{+}$as a function of the PS concentration and the gold coverage. The results are displayed for $(\mathbf{a}) \mathrm{Ga}^{+}$and $(\mathbf{b}) \mathrm{C}_{60}^{+}$primary ions. The lines are to guide the eyes The errors on the yield measurements do not exceed $8 \%$. 
instead of $\mathrm{C}_{60}^{+}$. Consequently, the best choice for maximum enhancement of the detection of the molecular adduct ion is the evaporation of $6 \mathrm{~nm}$ Au combined with $\mathrm{Ga}^{+}$projectile measurement.

Without metallization, the effect of the PS sample concentration on the characteristic secondary ion yields is dramatic and strongly dependent on the chosen projectile type (Figure 2). For atomic projectile bombardment, maximums in the yield versus concentration curves have been already reported for polymers such as PS [11], PMMA [12, 26], PVC [12], and for biological films [13]. Norrman et al. [12] spin-coated PMMA and PVC on Si wafers using a range of polymer concentrations. They found that the maximum ion yield is observed at $1 \mathrm{mg} / \mathrm{mL}$ for both polymers suggesting similar concentrations for what corresponds to $100 \%$ surface coverage. The thickness of the PMMA layer at 1 $\mathrm{mg} / \mathrm{mL}$ was found to be $\sim 6 \mathrm{~nm}$ and that of PVC, $\sim 2.7$ $\mathrm{nm}$. Above $2 \mathrm{mg} / \mathrm{mL}$, the yield decreased for both polymers. According to Muddiman et al. [11], the secondary ion yields of PS deposited on etched silver increase up to a concentration of about $4 \mathrm{mg} / \mathrm{mL}$, concentration at which the polymer forms a monolayer. Beyond $4 \mathrm{mg} / \mathrm{mL}$, a drastic yield decrease is observed. Another work conducted with amino-acids [13] reported a linear relationship between the SI yield and the surface concentration ranging from $1 \times 10^{13}$ to $5 \times 10^{14}$ arginine molecule $/ \mathrm{cm}^{2}$. The authors attributed these results to a complete monolayer of arginine being formed with $5 \times 10^{14}$ molecule $/ \mathrm{cm}^{2}$. Multiple layers were formed at higher concentrations. For all these works as well as our study, the characteristic ion yield maxima were observed in the monolayer regime. One interpretation was that, because the number of molecules that can be ionized due to direct interactions with the substrate becomes limited with increasing concentrations, the SI yields decrease and finally stabilize at a value corresponding to the bulk sample. Another interpretation directly involves the sputtering part of the process, because the energy confined and back-reflected from the Silicon substrate to the organic layer directly depends on the layer thickness. According to the transport of ions in matter (TRIM) program, based on Monte-Carlo calculation, the longitudinal range of 12 $\mathrm{keV} \mathrm{Ga}^{+}$primary ions in a thick ( $>23 \mathrm{~nm}$ ) layer of PS is about 17 to $18 \mathrm{~nm}$, while for a monolayer on silicon (3.5 $\mathrm{nm}$ ), it is reduced to $12 \mathrm{~nm}$ (Table 2). Better energy confinement in the surface should lead to higher sputtered yields of fragments and molecules. TRIM simulations also indicate that $\mathrm{Si}$ atoms should only be sputtered for PS thicknesses that are lower than $12 \mathrm{~nm}(<5$ $\mathrm{mg} / \mathrm{mL}$ ). Consistently, our experiments show that beyond $2 \mathrm{mg} / \mathrm{mL}$, the substrate signal, $\mathrm{Si}^{+}$, disappears.

The same sputtering argument can be proposed to interpret the new results reported for $\mathrm{C}_{60}^{+}$bombardment. Indeed, the longitudinal range of $200 \mathrm{eV} \mathrm{C}$ atoms in PS, which can be used as a first approximation for the range $12 \mathrm{keV} \mathrm{C}{ }_{60}$, is only $2.1 \mathrm{~nm}$. This value is actually below the considered monolayer thickness $(3.5 \mathrm{~nm})$.
Table 2. Longitudinal ranges of $12 \mathrm{keV} \mathrm{Ga}^{+}$projectiles in polystyrene layers spin-coated on $\mathrm{Si}$ and Au substrates with thicknesses ranging from 3.5 up to $45 \mathrm{~nm}^{*}$

\begin{tabular}{|c|c|c|}
\hline \multirow[b]{2}{*}{ PS thicknesses } & \multicolumn{2}{|c|}{$\begin{array}{l}\text { Longitudinal range }(\mathrm{nm}) \text { at } \\
\qquad 12 \mathrm{keV}\end{array}$} \\
\hline & $\mathrm{Si}$ & $\mathrm{Au}$ \\
\hline $3.5 \mathrm{~nm}$ & 11.8 & 6.5 \\
\hline $6 \mathrm{~nm}$ & 12.6 & 7.5 \\
\hline $12 \mathrm{~nm}$ & 14.8 & 11.9 \\
\hline $23 \mathrm{~nm}$ & 17.4 & 16.4 \\
\hline $45 \mathrm{~nm}$ & 17.6 & 16.6 \\
\hline
\end{tabular}

*The values are obtained using the "transport of ions in matter" (TRIM) program based on Monte-Carlo calculation.

Therefore, with this approximation, the $\mathrm{C}_{60}^{+}$projectile already deposits all of its energy in the spin-coated PS monolayer, without reaching the silicon substrate. This interpretation accommodates the observation that the secondary ion yields measured for PS concentrations higher than $1 \mathrm{mg} / \mathrm{mL}$ do not decrease but remain almost constant. Even though more sophisticated simulations show that the combined action of 60 carbon atoms induces collective effects, which eventually lead to somewhat larger depth for the projectile penetration and the deposited energy, they qualitatively agree with our interpretation based on TRIM calculations [27, 28].

In contrast to the pristine samples, the yields measured on gold-metallized samples do not decrease for high PS coverage. On the other hand, the yields increase or decrease continuously with the amount of evaporated gold depending whether $\mathrm{Ga}^{+}$or $\mathrm{C}_{60}^{+}$, respectively, are used as projectiles (Figures 2 and 3). An interpretation has already been proposed for this differential effect of the gold metallization in previous papers $[7,16$, 23]. Heile et al. have shown that deposition of 0.2 and 2 $\mathrm{nm}$ of gold lead to an enhancement of the secondary ion yield for all characteristic fragment ions emitted from PS samples bombarded with different atomic primary ions including $\mathrm{Ar}^{+}, \mathrm{Xe}^{+}, \mathrm{Ga}^{+}$, and $\mathrm{Bi}^{+}$[16]. They found that the use of polyatomic ion such as $\mathrm{Bi}_{3}^{+}, \mathrm{SF}_{5}^{+}$, and $\mathrm{C}_{60}^{+}$ leads to a decrease of the secondary ion yields with increasing gold deposition. The first element of the explanation was based on the assumption that organic layers tend to diffuse over the gold islets so that the final system mimics an organic layer adsorbed on metal. Molecular diffusion and/or cluster penetration could be demonstrated experimentally for the evaporation of various metals on different kinds of polymers [29-31]. In this new study, the morphology of the evaporated gold layer was checked using SEM. In agreement with previous works, the obtained micrographs indicate that the $\mathrm{Au}$ atoms coalesce to form droplet-like islands on the surface, as illustrated in Figure 1. For large gold coverage, leaving only small parts of the organic sample visible, the high measured yields of organic species would be difficult to explain without diffusion of PS on the gold [32]. Therefore, this hypothesis remains the most plausible. Second, the 
different mechanisms of energy deposition of atomic and polyatomic projectiles were invoked. While gold helps confine the projectile energy deposition in the portion of the surface that is useful for sputtering with $\mathrm{Ga}^{+}$and other atomic ions, it is detrimental for isoenergetic $\mathrm{C}_{60}^{+}$projectiles, because it only leads to projectile backscattering in the vacuum. Molecular dynamics simulations are underway to explore this phenomenon. Beyond pure sputtering effects, the strong yield enhancement observed upon $\mathrm{Ga}^{+}$bombardment also suggests that the gold nanoparticles play an important role in the ionization effect.

In the following section, the influence of the organic layer thickness on the gold atomic and cluster ions $\left(\mathrm{Au}_{n}^{+} ; 1 \leq n \leq 13\right)$ sputtered from metallized PS samples is investigated in detail.

\section{Emission of $\mathrm{Au}_{n}^{+}$Clusters}

The effect of evaporation of small $(0.5 \mathrm{~nm})$ quantities of gold onto PS films of different thicknesses $(0.1,1$ and 10 $\mathrm{mg} / \mathrm{mL}$ ), on the measured $\mathrm{Au}_{n}^{+}$yields, is illustrated in Figure 4 for $\mathrm{C}_{60}^{+}$projectile. The characteristic behavior of metal cluster emission from pure metal foils is also visible in the case of metal condensates. First, there is a steady decrease of the secondary ion yields as the number " $n$ " of $\mathrm{Au}_{n}^{+}$increases and, second, yield oscillations known as the odd-even effect, which means that ions detected with odd number " $n$ " of gold atoms are more intense that those detected with an even number [33-35]. The yield decrease with $n$ has been explained by MD simulations and the sputtering theory. Experimentally, we can not neglect the additional effect of the efficiency of the MCP detector, which decreases for ions of increasing masses [36]. The odd-even effect in the mass distribution of gold clusters reflects the odd-even

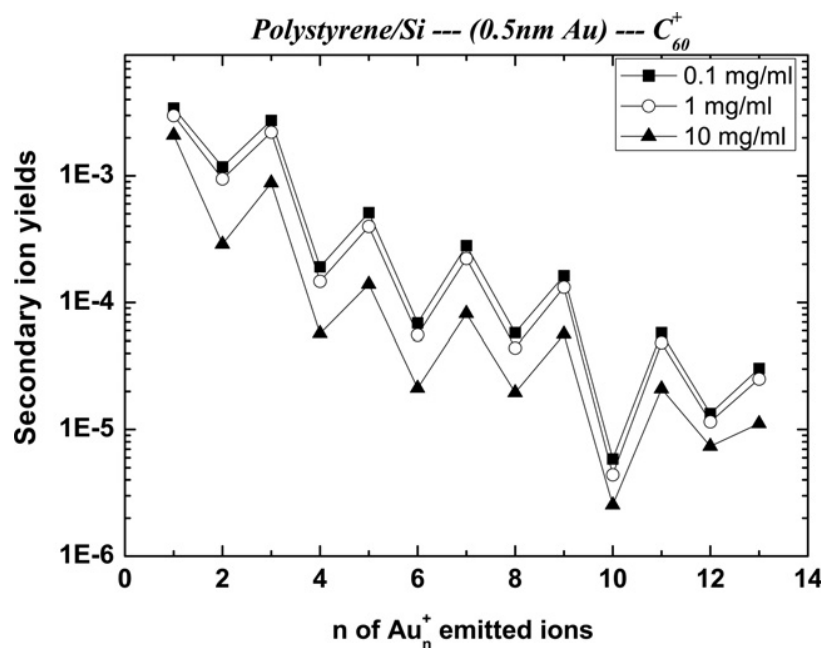

Figure 4. Variations of the secondary ion yields of $\mathrm{AU}_{n}^{+}$after evaporation of $0.5 \mathrm{~nm}$ of gold onto three different PS "layer thicknesses" $(0.1,1$ and $10 \mathrm{mg} / \mathrm{mL})$. The results are displayed for $\mathrm{C}_{60}^{+}$primary ion. The errors on the yield measurements do not exceed $7 \%$. alternation in electron affinities [37] and consequently in gold cation stability. The electronic shell structure [37] is also responsible for the increased stability of two specific clusters $\mathrm{Au}_{3}^{+}(n=3)$ and $\mathrm{Au}_{9}^{+}(n=9)$ and for the weakened stability of the next clusters $\mathrm{Au}_{4}^{+}(n=4)$ and $\mathrm{Au}_{10}^{+}(n=10)$ (Figure 4). Indeed $\mathrm{Au}_{3}^{+}$and $\mathrm{Au}_{9}^{+}$ correspond to the complete filling of the electronic shells $\left(6 s^{2}\right.$ and $\left(6 s^{2} 6 p^{6}\right.$, respectively.

Figure 4 shows that the measured yields of gold clusters, $\mathrm{Au}_{n}^{+}$, depend on the combined effect of gold and PS coverage. The yields are affected by the PS coverage for small gold thicknesses $(0.5 \mathrm{~nm})$. In that case, the ion yields increase as the PS coverage decreases irrespective of the primary ion nature. The yields are almost three times higher if PS is prepared as a monolayer $(1 \mathrm{mg} / \mathrm{mL})$ rather than a thick layer (10 $\mathrm{mg} / \mathrm{mL}$ ). This yield enhancement tends to saturate for PS coverage below one monolayer. A similar effect is observed upon $\mathrm{Ga}^{+}$bombardment. In contrast to 0.5 $\mathrm{nm}$, our experiments show that, with $6 \mathrm{~nm}$ of gold, the $\mathrm{Au}$ cluster yields do not depend on the PS layer thickness anymore; their values are very close whatever the PS layer thickness and this for both primary ions (figure not shown here).

It is useful to perform a more quantitative comparison of these results by considering two ratios. First, we compare the yields measured for each projectile but for the two different amounts of evaporated gold ( 0.5 and 6 $\mathrm{nm}$ ). We define the factor " $\alpha$ ", obtained by dividing the yields recorded for $6 \mathrm{~nm}$ of Au by those recorded for 0.5 $\mathrm{nm}$ of $\mathrm{Au}$, for each PS coverage: $\alpha=\frac{Y(6 n m A u)}{Y(0.5 n m A u)}$. This comparison is reported in Table $3 a$ and $b$, for $\mathrm{Ga}^{+}$and $\mathrm{C}_{60}^{+}$, respectively. Second, we compare the yields obtained with both projectiles but for the same amount of evaporated gold (yield enhancement). This comparison is represented by the factor $\beta=\frac{Y\left(C_{60}^{+}\right)}{Y\left(G a^{+}\right)}$and values are reported in Table $3 \mathrm{c}$ and $\mathrm{d}$.

For a given PS coverage, $\alpha$ decreases as the size of the detected cluster " $n$ " increases (Table 3 ), indicating that larger clusters are better detected for small gold coverages. Moreover, for a given cluster size " $n$ ", $\alpha$ increases with the PS coverage. Consequently, there is a limit value for " $n$ " beyond which $\mathrm{Au}_{n}^{+}$clusters are detected with higher yields when PS samples are metallized with $0.5 \mathrm{~nm} \mathrm{Au}(\alpha<1)$. For $\mathrm{Ga}^{+}$projectiles, this limit is for $n=6$ with $0.1 \mathrm{mg} / \mathrm{mL}$ of PS and for $n=12$ with 1 $\mathrm{mg} / \mathrm{mL}$ of PS. Finally, the calculated $\alpha$ for thick PS coverage $(10 \mathrm{mg} / \mathrm{mL})$ are all found to be higher than one, which means that gold clusters are all detected with higher yields if $6 \mathrm{~nm}$ of $\mathrm{Au}$ are evaporated onto a thick PS layer instead of $0.5 \mathrm{~nm}$ of Au. Similar observations apply for $\mathrm{C}_{60}^{+}$(Table $3 \mathrm{~b}$ ) but the limit values for " $n$ " are much lower than those found for $\mathrm{Ga}^{+}$. The values of $\alpha$ are in general found to be lower than 1 , which means that almost all gold clusters are detected with higher yields if $0.5 \mathrm{~nm} \mathrm{Au}$ is evaporated onto PS 
Table 3. Values of $\alpha(\mathrm{a}, \mathrm{b})$ and $\beta$ (c, d) factors for $\mathrm{Au}_{n}^{+}$ions ( $n=1$ up to 13) calculated from three different PS layer thicknesses $(0.1,1 \text {, and } 10 \mathrm{mg} / \mathrm{mL})^{*}$

\begin{tabular}{|c|c|c|c|c|c|c|c|c|c|c|c|c|}
\hline \multirow[b]{2}{*}{$\begin{array}{c}\text { No of } \\
\mathrm{Au}_{n}^{+}\end{array}$} & \multicolumn{3}{|c|}{$\begin{array}{c}\text { (a) } \mathrm{Ga}^{+} \\
\alpha=\mathrm{Y}(6 \mathrm{~nm} / 0.5 \mathrm{~nm} \mathrm{Au})\end{array}$} & \multicolumn{3}{|c|}{$\begin{array}{c}\text { (b) } \mathrm{C}_{60}^{+} \\
\alpha=\mathrm{Y}(6 \mathrm{~nm} / 0.5 \mathrm{~nm} \mathrm{Au})\end{array}$} & \multicolumn{3}{|c|}{$\begin{array}{l}\text { (c) } 0,5 \mathrm{~nm} \mathrm{Au} \\
\beta=\mathrm{Y}\left(\mathrm{C}_{60}^{+} / \mathrm{Ga}^{+}\right)\end{array}$} & \multicolumn{3}{|c|}{$\begin{array}{c}\text { (d) } 6 \mathrm{~nm} \mathrm{Au} \\
\beta=\mathrm{Y}\left(\mathrm{C}_{60}^{+} / \mathrm{Ga}^{+}\right)\end{array}$} \\
\hline & $\begin{array}{c}0.1 \\
\mathrm{mg} / \mathrm{mL}\end{array}$ & $\begin{array}{c}1 \\
\mathrm{mg} / \mathrm{mL}\end{array}$ & $\begin{array}{c}10 \\
\mathrm{mg} / \mathrm{mL}\end{array}$ & $\begin{array}{c}0.1 \\
\mathrm{mg} / \mathrm{mL}\end{array}$ & $\begin{array}{c}1 \\
\mathrm{mg} / \mathrm{mL}\end{array}$ & $\begin{array}{c}10 \\
\mathrm{mg} / \mathrm{mL}\end{array}$ & $\begin{array}{c}0.1 \\
\mathrm{mg} / \mathrm{mL}\end{array}$ & $\begin{array}{c}1 \\
\mathrm{mg} / \mathrm{mL}\end{array}$ & $\begin{array}{c}10 \\
\mathrm{mg} / \mathrm{mL}\end{array}$ & $\begin{array}{c}0.1 \\
\mathrm{mg} / \mathrm{mL}\end{array}$ & $\begin{array}{c}1 \\
\mathrm{mg} / \mathrm{mL}\end{array}$ & $\begin{array}{c}10 \\
\mathrm{mg} / \mathrm{mL}\end{array}$ \\
\hline 1 & 1.9 & 2.9 & 5.1 & 1.0 & 1.2 & 1.4 & 5 & 6 & 8 & 3 & 2 & 2 \\
\hline 2 & 1.4 & 1.6 & 4.7 & 0.4 & 0.5 & 1.1 & 88 & 69 & 73 & 22 & 19 & 17 \\
\hline 3 & 1.9 & 3.0 & 7.8 & 0.4 & 0.5 & 1.1 & 51 & 53 & 68 & 11 & 9 & 10 \\
\hline 4 & 1.4 & 2.4 & 6.3 & 0.3 & 0.5 & 1.0 & 80 & 78 & 85 & 19 & 15 & 14 \\
\hline 5 & 1.3 & 2.1 & 6.3 & 0.3 & 0.4 & 1.0 & 44 & 45 & 51 & 10 & 9 & 8 \\
\hline 6 & 1.1 & 1.7 & 5.8 & 0.3 & 0.4 & 0.9 & 31 & 33 & 45 & 8 & 7 & 7 \\
\hline 7 & 0.9 & 1.5 & 5.2 & 0.2 & 0.3 & 0.7 & 35 & 39 & 53 & 9 & 8 & 7 \\
\hline 8 & 0.7 & 1.5 & 4.9 & 0.2 & 0.3 & 0.5 & 37 & 40 & 48 & 9 & 8 & 5 \\
\hline 9 & 0.6 & 1.3 & 4.6 & 0.1 & 0.2 & 0.5 & 30 & 33 & 48 & 6 & 6 & 5 \\
\hline 10 & 0.6 & 1.7 & 4.6 & 0.1 & 0.2 & 0.4 & 17 & 19 & 16 & 4 & 2 & 1 \\
\hline 11 & 0.4 & 1.0 & 4.4 & 0.1 & 0.2 & 0.4 & 41 & 54 & 73 & 11 & 9 & 7 \\
\hline 12 & 0.5 & 1.3 & 5.3 & 0.1 & 0.1 & 0.3 & 67 & 67 & 82 & 11 & 6 & 5 \\
\hline 13 & 0.4 & 0.7 & 4.0 & 0.1 & 0.1 & 0.3 & 33 & 37 & 49 & 6 & 6 & 4 \\
\hline
\end{tabular}

${ }^{*} \alpha$ Factors are obtained by dividing yields recorded for $6 \mathrm{~nm}$ of Au by those recorded for $0.5 \mathrm{~nm}$ of Au and this for each PS coverage: $\alpha=\mathrm{Y}(6$ $\mathrm{nmAu}) / \mathrm{Y}(0.5 \mathrm{nmAu}) ; \beta$ factors are obtained by dividing yields recorded upon $\mathrm{C}_{60}^{+}$by those recorded upon $\mathrm{Ga}^{+}$for the same amount of evaporated gold: $\beta=\mathrm{Y}\left(\mathrm{C}_{60}^{+}\right) / \mathrm{Y}\left(\mathrm{Ga}^{+}\right)$.

samples instead of $6 \mathrm{~nm}$. For comparison, we made the same experiments by evaporating 0.5 and $6 \mathrm{~nm}$ of gold directly to the Si substrate, without polystyrene. The measured $\alpha$ values were, for both projectiles, very similar to those obtained in the case of very thin PS layers $(0.1 \mathrm{mg} / \mathrm{mL})$ spin-coated onto silicon substrate. This result indicates that with or without PS submonolayer, the sputtering behavior of the gold layer is the same, probably because the evaporated gold is interacting with the silicon substrate in both cases.

The yield enhancements obtained using $\mathrm{C}_{60}^{+}$projectiles $(\beta)$ are listed in Table $3 \mathrm{c}$ and $\mathrm{d}$. The calculated $\beta$ values are all higher than 1 , which means that $\mathrm{Au}_{n}^{+}$are detected with higher yields using $\mathrm{C}_{60}^{+}$for all cluster sizes $(n)$, for all PS concentrations and for both Au layer thicknesses. Nevertheless, the calculated $\beta$ values are much higher for $0.5 \mathrm{~nm}$ of $\mathrm{Au}$, which indicates that $\mathrm{C}_{60}^{+}$ is relatively more efficient than $\mathrm{Ga}^{+}$for the detection of gold ions, provided that the evaporated gold quantity is small. For instance, the $\beta$ value calculated for $\mathrm{Au}_{7}^{+}(n=$ 7 ) is close to 8 for a PS monolayer metallized with $6 \mathrm{~nm}$ of Au whereas the value is close to 40 if the gold amount is reduced to $0.5 \mathrm{~nm}$. Again, the yield enhancements, $\beta$, measured on samples without PS, are very close to those measured with PS submonolayers $(0.1 \mathrm{mg} / \mathrm{mL})$. Finally, the systematically lower $\beta$ values obtained for the atomic ion $\mathrm{Au}^{+}$, compared with $\mathrm{Au}_{n}^{+}$clusters, means that $\mathrm{C}_{60}^{+}$is comparatively more efficient for the ionization of large gold cluster than atomic ions.

Figure 4 indicates that it is harder to detect gold clusters from thick PS layers $(10 \mathrm{mg} / \mathrm{mL})$ on which a small quantity of gold is evaporated $(0.5 \mathrm{~nm})$. One explanation might be that the small gold nanoparticles diffuse into the thick PS layer, making the gold atoms less accessible for sputtering. In particular the evaporation of $0.5 \mathrm{~nm}$ of gold onto $1.5 \mathrm{~nm}$ of PS $(0.1 \mathrm{mg} / \mathrm{mL})$ provides the highest $\mathrm{Au}_{n}^{+}$ion yield because this system is equivalent than evaporating metal (gold) on silicon substrate. It should be pointed out that, for the same system of $0.5 \mathrm{~nm}$ Au evaporated on PS layers, the fragment and molecular secondary ion yields behave in an opposite way (Figures 2 and 3). In contrast to $\mathrm{Au}_{n}^{+}$ clusters, the yields of $\mathrm{C}_{7} \mathrm{H}_{7}^{+}$and $(\mathrm{M}+\mathrm{Au})^{+}$are the lowest for very thin $(0.1 \mathrm{mg} / \mathrm{mL})$ PS thickness, and they are maximal and constant for layer thicknesses ranging between 2 to $20 \mathrm{mg} / \mathrm{mL}$. In other words, with 0.5 $\mathrm{nm}$ of $\mathrm{Au}$ evaporated onto PS, when $\mathrm{Au}_{n}^{+}$clusters are detected with the largest yields, the fragment and cationized molecular ions are detected with the lowest yields. This result is consistent with our explanation above. Finally, with the evaporation of $6 \mathrm{~nm}$ of $\mathrm{Au}$, the PS thickness does not affect the $\mathrm{Au}_{n}^{+}$yields (figure not shown here). It is very likely that in such case, the gold layer remains totally accessible to the ion beam because it forms a massively interconnected network of islands unable to diffuse in the PS layer. This interconnected gold network also cancels sample charging.

With $\mathrm{C}_{60}^{+}$projectiles, the $\mathrm{Au}_{n}^{+}$clusters are detected with the best yields when the PS layers are metallized with the lowest gold coverage $(\alpha<1$ in Table 3$)$, in contrast to the $\mathrm{Ga}^{+}$case $(\alpha>1)$. This behavior has been already observed for molecular alkane layers metallized with various gold thicknesses [7]. In that study, the $\mathrm{Au}_{n}^{+}$ cluster yields decreased continuously as the gold coverage increased for polyatomic projectiles such as $\mathrm{C}_{60}^{+}$. This evolution was tentatively explained on the basis of the specifics of the sputtering process, considering the different energy deposition depth of different projectiles [7]. TRIM calculations performed for our systems show that the $\mathrm{Ga}^{+}$range is between 10 and $22 \mathrm{~nm}$, 
while it does not exceed $2 \mathrm{~nm}$ in the case of $\mathrm{C}_{60}^{+}$. For $\mathrm{C}_{60}^{+}$, it was proposed that the $\mathrm{Au}_{n}^{+}$yields decrease with coverage simply because their average binding energy to the surface increases with increasing gold coverage. In contrast, for $\mathrm{Ga}^{+}$primary ions, thicker gold layers increase the energy confinement. Consequently, the $\mathrm{Au}_{n}^{+}$yields do not decrease for high gold coverage because the increased energy confinement in the surface offsets the increase of the binding energy.

\section{Comparison Between Si and Au Substrates}

To check the substrate effect and to compare it with the various results shown above, additional measurements were performed with a gold substrate (instead of silicon). Yield variations as a function of PS coverage on silicon and gold substrates are presented in Table 4 for the fragment $\mathrm{C}_{7} \mathrm{H}_{7}^{+}$and for the adduct molecular ion $(\mathrm{M}+\mathrm{Au})^{+}$, upon $\mathrm{Ga}^{+}$and $\mathrm{C}_{60}^{+}$bombardment. Results obtained on metallized PS are also included for comparison purpose. Table 4 indicates that the different substrates induce very different characteristic ion yields of $\mathrm{C}_{7} \mathrm{H}_{7}^{+}$with $\mathrm{Ga}^{+}$projectiles but not with $\mathrm{C}_{60}^{+}$. For PS (sub)monolayers under $\mathrm{Ga}^{+}$impacts, the $\mathrm{C}_{7} \mathrm{H}_{7}^{+}$yields are more than one order of magnitude larger on gold than silicon. The gold substrate provides even larger yield enhancements than gold condensates for the same PS layers. This is also true for the adduct $(\mathrm{M}+\mathrm{Au})^{+}$ ion. The yield measured for this ion is almost six times larger for PS monolayers on gold than for Au-metallized layers (6 nm Au). For thicker PS coatings (5 and 20 $\mathrm{mg} / \mathrm{mL}$ ) the substrate effect disappears, adduct ion yields level off and the characteristic ion yields $\left(\mathrm{C}_{7} \mathrm{H}_{7}^{+}\right)$ tend to the same value irrespective of the substrate nature. Those yields are more than one order of magnitude lower than the yields measured for PS monolayers on gold substrate.
The situation is very different with $\mathrm{C}_{60}^{+}$. In this case, both substrates induce similar yields of fingerprint $\mathrm{C}_{7} \mathrm{H}_{7}^{+}$fragments. The evaporation of gold onto pristine samples also reduces the yields significantly, as was discussed previously. Therefore, the highest yields of fragment ions are obtained from samples without any treatment (pristine). The yields measured for thin and thick PS spin-coated on gold or silicon substrates are, respectively, one and two orders of magnitude higher with $\mathrm{C}_{60}^{+}$than $\mathrm{Ga}^{+}$primary ions. Upon $\mathrm{C}_{60}^{+}$bombardment, it is not clear that the use of a gold substrate can lead to higher yields of $(\mathrm{M}+\mathrm{Au})^{+}$adduct ions than the metallization procedure. Also, for monolayer coverage, the absolute yield of $(\mathrm{M}+\mathrm{Au})^{+}$is lower than that measured with $\mathrm{Ga}^{+}$, which constitutes a striking contrast with the fragment case. To maximize the adduct molecular ion yield under $\mathrm{C}_{60}^{+}$bombardment, the best approach is to evaporate a minimal amount of gold onto the PS surface $(0.5 \mathrm{~nm})$.

The substrate effect clearly depends on the projectile nature. According to Table 1, the same concentration of polystyrene spin-coated on both substrates gives rise to almost the same measured thicknesses, so that this factor can be neglected to explain the effects observed in Table 4. Upon $\mathrm{Ga}^{+}$bombardment, the emission of ionized material is higher when gold is used as substrate. This feature of increasing sensitivity by using noble metal substrate $(\mathrm{Au}, \mathrm{Ag})$ has been largely exploited to study biological $[10,38,39]$ and polymer $[4,9$, $11,40]$ materials. Previous studies emphasize that as the layer thickness decreases, the yields of molecular adduct ions such as $(\mathrm{M}+\mathrm{Me})^{+}$increases in abundance relative to molecular $(\mathrm{M}+\mathrm{H})^{+}$ion. For PS spin-coated on various substrates $[8,41]$, metals such as gold and silver provide high cationization efficiency, whereas silicon and aluminium do not cationize at all. It has also been argued that the efficiency of cationization in vacuo

Table 4. Secondary ion yield variations as a function of PS concentration spin-coated on silicon (pristine) and gold substrates for the fragment $\left(\mathrm{C}_{7} \mathrm{H}_{7}^{+}\right)$and for the adduct molecular ion $(\mathrm{M}+\mathrm{Au})^{+*}$

\begin{tabular}{|c|c|c|c|c|c|c|}
\hline & $\mathrm{PS} \mathrm{mg} / \mathrm{mL}$ & $\mathrm{PS} / \mathrm{Si}$ & $0.5 \mathrm{~nm} \mathrm{Au}$ & $2 \mathrm{~nm} \mathrm{Au}$ & $6 \mathrm{~nm} \mathrm{Au}$ & $\mathrm{PS} / \mathrm{Au}$ \\
\hline \multirow[t]{2}{*}{$\mathrm{Ga}^{+}$} & 0.1 & 1.27E-04 & 2.62E-04 & $2.58 \mathrm{E}-04$ & $3.32 \mathrm{E}-04$ & $2.08 \mathrm{E}-03$ \\
\hline & 1 & $6.70 \mathrm{E}-04$ & 6.31E-04 & $1.30 \mathrm{E}-03$ & $1.60 \mathrm{E}-03$ & $3.75 \mathrm{E}-03$ \\
\hline \multirow[t]{2}{*}{$\mathrm{C}_{7} \mathrm{H}_{7}^{+}$} & 5 & $1.72 \mathrm{E}-04$ & $1.60 \mathrm{E}-03$ & $2.80 \mathrm{E}-03$ & $3.10 \mathrm{E}-03$ & $1.90 \mathrm{E}-04$ \\
\hline & 20 & $1.45 \mathrm{E}-04$ & $1.40 \mathrm{E}-03$ & $2.80 \mathrm{E}-03$ & $3.10 \mathrm{E}-03$ & $1.65 \mathrm{E}-04$ \\
\hline \multirow[t]{2}{*}{$\mathrm{C}_{60}^{+}$} & 0.1 & $1.29 \mathrm{E}-02$ & 1.07E-02 & $3.40 \mathrm{E}-03$ & $2.30 \mathrm{E}-03$ & $1.60 \mathrm{E}-02$ \\
\hline & 1 & $5.85 \mathrm{E}-02$ & $2.30 \mathrm{E}-02$ & $1.71 \mathrm{E}-02$ & 8.80E-03 & 5.11E-02 \\
\hline \multirow[t]{2}{*}{$\mathrm{C}_{7} \mathrm{H}_{7}^{+}$} & 5 & 5.89E-02 & 4.36E-02 & 4.24E-02 & 2.66E-02 & $4.98 \mathrm{E}-02$ \\
\hline & 20 & 5.99E-02 & 4.15E-02 & 3.83E-02 & $2.22 \mathrm{E}-02$ & 5.00E-02 \\
\hline \multirow[t]{2}{*}{$\mathrm{Ga}^{+}$} & 0.1 & & 1.67E-07 & 2.87E-07 & 1.27E-06 & $9.16 \mathrm{E}-06$ \\
\hline & 1 & & 5.45E-07 & 3.94E-06 & $1.26 \mathrm{E}-05$ & 7.08E-05 \\
\hline \multirow[t]{2}{*}{$(M+A u)^{+}$} & 5 & & $6.43 \mathrm{E}-06$ & 2.31E-05 & 3.43E-05 & $2.23 \mathrm{E}-07$ \\
\hline & 20 & & 4.12E-06 & $2.02 \mathrm{E}-05$ & 3.80E-05 & $1.25 \mathrm{E}-08$ \\
\hline \multirow[t]{2}{*}{$\mathrm{C}_{60}^{+}$} & 0.1 & & 1.84E-05 & $9.98 \mathrm{E}-06$ & 5.85E-06 & $1.48 \mathrm{E}-05$ \\
\hline & 1 & & $1.90 \mathrm{E}-05$ & 1.17E-05 & 8.09E-06 & 4.18E-05 \\
\hline \multirow[t]{2}{*}{$(M+A u)^{+}$} & 5 & & 5.49E-05 & $3.78 \mathrm{E}-05$ & 1.92E-05 & 5.13E-06 \\
\hline & 20 & & 4.57E-05 & $3.44 \mathrm{E}-05$ & $1.80 \mathrm{E}-05$ & $5.38 \mathrm{E}-06$ \\
\hline
\end{tabular}

*Results are displayed for $\mathrm{Ga}^{+}$and $\mathrm{C}_{60}^{+}$projectiles. Results are also compared with pristine PS on which gold is evaporated with three different thicknesses $(0.5,2$, and $6 \mathrm{~nm} \mathrm{Au})$. The errors on the yield measurements do not exceed $8 \%$. 
should depend on the number of metal atoms sputtered in their excited-state and that metastable atoms with an excited d level $(\mathrm{Au}, \mathrm{Ag})$ have a good chance to keep their excitation while leaving the surface. A better understanding of the different influence of the two substrates on ionization would require detailed electronic structure calculations and is outside the scope of this study. From the point of view of sputtering, the results of TRIM calculations in Table 2 show that the range of $\mathrm{Ga}^{+}$is $40 \%$ lower for monolayers of PS on $\mathrm{Au}$ substrates than for the same layers on $\mathrm{Si}$. In consequence, the projectile energy is better confined in the surface region using gold substrates, which is consistent with larger sputtering yields of organic material. Our calculations finally indicate that the range of values for $\mathrm{Au}$ and Si substrates tend to converge as the PS thickness increases. They become similar for PS layers thicker than $2 \mathrm{mg} / \mathrm{mL}$ (6 nm PS), which explains the fact that the substrate effect disappear for thick PS layers ( 5 and $20 \mathrm{mg} / \mathrm{mL}$ ).

On the other hand, the substrate effect is absent with $\mathrm{C}_{60}^{+}$, since the fingerprint ion yields are almost the same for PS spin-coated on gold and silicon. If we consider that the absence of the substrate effect can be understood for thick PS layers, it is certainly not the case for thin layers. The comparatively low yields of $(\mathrm{M}+\mathrm{Au})^{+}$ adduct ions also confirm the limited efficiency of the cationization process upon fullerene impacts. Additional experiments still have to be made to understand such behavior.

\section{Conclusions}

The attempts to vary different factors that affect the SIMS spectra allowed us to find combinations that can be either beneficial or disadvantageous for polymer analysis. For polystyrene (sub)monolayers under $\mathrm{Ga}^{+}$ ion beam analysis, gold substrates provide the best results. To enhance the yields further, $\mathrm{C}_{60}^{+}$projectiles should be used. For the same (sub)monolayers, the yield is then enhanced by one order of magnitude in comparison with $\mathrm{Ga}^{+}$projectile. In addition, the choice of substrate is irrelevant with $\mathrm{C}_{60}^{+}$(the yields are similar for silicon and gold substrates). For thick (or bulk) PS samples, a very effective way to increase the peak intensities, upon $\mathrm{Ga}^{+}$impact, is to metallize the sample by $6 \mathrm{~nm}$ of gold (the fragment yields increase by one order of magnitude). However, the use of $\mathrm{C}_{60}^{+}$projectiles remains the best choice for thick PS samples, since the fingerprint ion yields increase by more than two orders of magnitude compared with $\mathrm{Ga}^{+}$. The significant benefit of metallization observed with $\mathrm{Ga}^{+}$disappears with $\mathrm{C}_{60}^{+}$, for which the yield decreases continuously with the gold coverage. The observed effects were tentatively explained by the difference of energy deposition between atomic, $\mathrm{Ga}^{+}$, and polyatomic, $\mathrm{C}_{60}^{+}$, projectiles leading to different dynamics of sputtering in TOFSIMS.

\section{Acknowledgments}

The authors acknowledge the European Community for funding N.W. and supporting this work through the Network of Excellence Nanobeams (contract no. NMP4-CT-2004-500440). The authors are also grateful to the Communauté Française de Belgique for financial support (Action de Recherches Concertée 07/12-003 NANHYMO. A.D. thanks the Belgian Fonds National pour la Recherche Scientifique (FNRS) for financial support. T.M. acknowledges the support of the European Community via the FP7 project 3D NanoChemiscope (grant agreement CP-TP 200613-2).

\section{References}

1. Benninghoven, A.; Rüdenauer, F. G.; Werner, H. W. Secondary Ion Mass Spectrometry, Chemical Analysis, Vol. LXXXVI, Wiley: New York, 1987;

2. Benninghoven, A.; Loebach, E. The Analysis of Monomolecular Layers of Solids by the Static Method of Secondary Ion Mass Spectroscopy (SIMS). J. Radioanal. Chem. 1972, 12, 95-99.

3. Galuska, A. A. TOF-SIMS Determination of Molecular Weights from Polymeric Surfaces and Microscopic Phases. Surf. Int. Anal. 1997, 25, $790-798$.

4. Blestos, I. V.; Hercules, D. M.; van Leyen, D.; Hagenhoff, B.; Niehuis, E.; Benninghoven, A. Molecular Weight Distributions of Polymers Using Time-of-Flight Secondary-Ion Mass Spectrometry. Anal. Chem. 1991, 63, 1953-1960.

5. Altelaar, A. F. M.; van Minnen, J.; Jimenez, C. R.; Heeren, R. M. A.; Piersma, S. R. Direct Molecular Imaging of Lymnaea stagnali Nervous Tissue at Subcellular Spatial Resolution by Mass Spectrometry. Anal. Chem. 2005, 77(3), 735-741.

6. Sjovall, P.; Lausmaa, J.; Johansson, B. Mass Spectrometric Imaging of Lipids in Brain Tissue. Anal. Chem. 2004, 76, 4271-4278.

7. Wehbe, N.; Heile, A.; Arlinghaus, H. F.; Bertrand, P.; Delcorte, A. Effects of Metal Nanoparticles on the Secondary Ion Yields of a Model Alkane Molecule upon Atomic and Polyatomic Projectiles in Secondary Ion Mass Spectrometry. Anal. Chem. 2008, 80, 6235-6244.

8. Delcorte, A.; Wojciechowski, I.; Gonze, X.; Garrison, B. J.; Bertrand, P. Single and Double Cationization of Organic Molecules in SIMS. Int. J. Mass Spectrom. 2002, 214, 213-232.

9. Hagenhoff, B.; Deimel, M.; Benninghoven, A. Siegmund, H.-U.; Holtkamp, D. Analysis of Langmuir-Blodgett Overlayers by Time-of-Flight Secondary Ion Mass Spectrometry (TOF-SIMS). J. Phys. D 1992, 25, $818-832$.

10. Cornelio, P. A.; Gardella, J. A., Jr. Langmuir Blodgett film-Metal Interfaces. Static Secondary Ion Mass Spectrometry and Electron Spectroscopy for Chemical Analysis. Metallization of Polymers. Proceedings of the ACS Symposium; Series 440. Montreal, Quebec, September, 1989; Chap 28, p. 379.

11. Muddiman, D. C.; Brockman, A. H.; Proctor, A.; Houalla, M.; Hercules, D. Characterization of Polystyrene on Etched Silver using Ion Scattering and X-Ray Photoelectron Spectroscopy Correlation of Secondary Ion Yield in Time-of-Flight SIMS with surface Coverage. J. Phys. Chem. 1994, 98, 11570-11575.

12. Norrman, K.; Haugshoj, K. B.; Larsen, N. B. Lateral and Vertical Quantification of Spin-Coated Polymer Films on Silicon by TOF-SIMS XPS, and AFM. J. Phys. Chem. B 2002, 106, 13114-13121.

13. Tamaki, S.; Sichtermann, W.; Benninghoven, A. Static SIMS Investigation of Ag-Supported Amino Acids. Jpn J. Appl. Phys. 1984, 23, 544-549.

14. Altelaar, A. F.; Klinkert, I.; Jalink, K.; de Lange, R. P.; Adan, R. A.; Heeren, R. M.; Piersma, S. R. Gold-Enhanced Biomolecular Surface Imaging of Cells and Tissue by SIMS and MALDI Mass Spectrometry. Anal. Chem. 2006, 78, 734-742.

15. Delcorte, A.; Médard, N.; Bertrand, P. Organic Secondary Ion Mass Spectrometry: Sensitivity Enhancement by Gold Deposition. Anal. Chem. 2002, 74, 4955-4968.

16. Heile, A.; Lipinsky, D.; Wehbe, N.; Delcorte, A.; Bertrand, P.; Felten, A.; Houssiau, L.; Pireaux, J.-J.; De Mondt, R.; Van Vaeck, L.; Arlinghaus, H. F. Metal-Assisted SIMS and Cluster Ion Bombardment for Ion Yield Enhancement. Appl. Surf. Sci. 2008, 255, 941-943.

17. McDonnell, L. A.; Heeren, R. M. A.; de Lange, R. P. J.; Fletcher, I. W. Higher Sensitivity Secondary Ion Mass Spectrometry of Biological Molecules for High Resolution, Chemically Specific Imaging. J. Am. Soc. Mass Spectrom. 2006, 17, 1195-1202.

18. Delcorte, A.; Bertrand, P. Interest of Silver and Gold Metallization for Molecular SIMS and SIMS imaging. Appl. Surf. Sci. 2004, 231/232, 250-255.

19. Brunelle, A.; Della-Negra, S.; Deprun, C.; Depauw, J.; Hakansson, P.; Jacquet, D.; le Beyec, Y.; Pautrat, M. High Desorption-Ionization Yields of Large Biomolecules Induced by Fast C60 Projectiles. Int. J. Mass Spectrom. Ion Processes 1997, 164, 193-200.

20. Rajagopalachary, S.; Verkhoturov, S. V.; Schweikert, E.-A. Characterization of Individual Ag Nanoparticles and Their Chemical Environment. Anal. Chem. 2009, 81, 1089-1094. 
21. Gillen, G.; Roberson, S. Preliminary Evaluation of an $\mathrm{SF}_{5}^{+}$Polyatomic Primary Ion Beam for Analysis of Organic Thin Films by Secondary Ion Mass Spectrometry. Rapid Commun. Mass Spectrom. 1998, 12, 1303-1312.

22. Kordys, J.; Fletcher, J. S.; Lockyer, N. P.; Vickerman, J. C. Substrate Effects on the Analysis of Biomolecular Layers Using $\mathrm{Au}^{+}, \mathrm{Au} 84_{3}^{+}$and $\mathrm{C}_{60}^{+}$Bombardments. Appl. Surf. Sci. 2008, 255, 890-892.

23. Delcorte, A.; Yunus, S.; Wehbe, N.; Nieuwjaer, N.; Poleunis, C.; Felten, A.; Houssiau, L.; Pireaux, J.-J.; Bertrand, P. Metal-Assisted Secondary Ion Mass Spectrometry Using Atomic $\left(\mathrm{Ga}^{+}, \mathrm{In}^{+}\right)$and Fullerene Projectiles. Anal. Chem. 2007, 79, 3673-3689.

24. Delcorte, A.; Vanden Eynde, X.; Bertrand, P.; Reich, D. F. Influence of the Primary Ion Beam Parameters (nature, energy, and angle) on the Kinetic Energy Distribution of Molecular Fragments Sputtered from Poly(Ethylene Terephthalate) by Kiloelectron Volt Ions. Int. J. Mass Spectrom. 1999, 189, 133-146.

25. Gilmore, I. S.; Seah, M. P. Ion Detection Efficiency in SIMS: Dependencies on Energy, Mass, and Composition for Microchannel Plates Used in Mass Spectrometry. Int. J. Mass Spectrom. 2000, 202, 217-229.

26. Leeson, A. M.; Alexander, M. R.; Short, R. D.; Hearn, M. J.; Briggs, D. Quantitative TOF SIMS Analysis of Spun-Cast and Solution-Cast Polymer Films. Int. J. Polymer. Anal. Charact. 1997, 4, 133-151.

27. Delcorte, A.; Garisson, B. J. Sputtering Polymers with Buckminsterfullerene Projectiles: A Coarse-Grain Molecular Dynamics Study. J. Phys. Chem. C 2007, 111, 15312-15324

28. Delcorte, A.; Wehbe, N.; Bertrand, P.; Garisson, B. Sputtering of Organic Molecules by Clusters, with Focus on Fullerenes. Appl. Surf. Sci. 2008, 255, 1229-1234.

29. Domingue, A.; Dignard-Bailey, L.; Sahcer, E.; Yelon, A.; Ellis, T. H. Reaction During Sputtering of Metals onto Polyimide. Metallization of polymers. Proceedings of the ACS Symposium; Series 440. Montreal, Quebec, September, 1989; Chap 20, p. 272.

30. Whitten, J. E. Gomer, R. Deposition of $\mathrm{Ni}$ and $\mathrm{Ag}$ on Benzene Multilayers Adsorbed on W (110). J. Phys. Chem. 1996, 100, 2255-2259.

31. Pattabi, M.; Rao, K. M.; Sainkar, S. R.; Sastry, M. Structural Studies on Silver Cluster Films Deposited on Softened PVP Substrates. Thin Solid Films 1999, 338, 40-45.
32. Prabhakaran, A.; Yunus, S.; Wehbe, N.; Bertrand, P.; Delcorte, A Secondary Ion Yield Enhancement in Organic Samples Due to Au/Pt Nanoparticle Condensation and Their Substrate Effects, unpublished (submitted).

33. Fallavier, M.; Kirsch, R.; Morozov, S. N.; Poizat, J. C.; Thomas, J. P.; Wehbe, N. Intense Emission of Cluster Anions from Gold Targets under Impact of $\mathrm{keV} / \mathrm{u}$ Gold Clusters. Phys. Rev. B 2003, 68, 140102 (1-4).

34. Stoermer, C.; Friedrich, J.; Kappes, M. M. Observation of Multiply Charged Cluster Anions upon Pulsed UV Laser Ablation of Meta Surfaces under High Vacuum Int. J. Mass Spectrom. 2001, 206, 63-78.

35. Katakuse, I.; Ichihara, T.; Fujita, Y.; Matsuo, T.; Sakurai, T.; Matsuda, H Mass Distributions of Negative Cluster Ions of Copper, Silver, and Gold. Int. J. Mass Spectrom. Ion Processes 1986, 74, 33-41.

36. Taylor, K. J.; Pettiette-Hall, C. L.; Chesnovsky, O.; Smalley, R. E. Ultraviolet Photoelectron Spectra of Coinage Metal Clusters. J. Chem. Phys. 1992, 96, 3319-3329.

37. Begemann, W.; Meiwes-Broer, K. H.; Lutz, H. O. Unimolecular Decomposition of Sputtered $\mathrm{Al}_{n}^{+}, \mathrm{Cu}_{n}^{+}$, and $\mathrm{Si}_{n}^{+}$Clusters. Phys. Rev. Lett. 1986, $56,2248-2251$.

38. Linton, R. W.; Lee, J. J.; Guarisco, V. F.; Hagenhoff, B.; Benninghoven, A Molecular Characterization of Biomimetic Surfaces using TOF-SIMS. Proceedings of the 8th International Conference on Secondary Ion Mass Spectrometry (SIMS VIII); International Congress Centre RAI, Amsterdam, The Netherlands, September, 1991; p. 823.

39. Amster, I. J.; Loo, J. A.; Furlong, J. J. P.; McLafferty, F. W. Cesium Ion Desorption Ionization with Fourier Transform Mass Spectrometry. Anal. Chem. 1987, 59, 313-317.

40. van Leyen, D.; Deimel, M.; Hagenhoff, B.; Benninghoven, A. Systematic Investigations of the Secondary Ion Formation from Compact Polymer Materials: Polymethylmethacrylate and Polyethyleneglycol. Proceedings of the 8th International Conference on Secondary Ion Mass Spectrometry (SIMS VIII); International Congress Centre RAI, Amsterdam, The Netherlands, September 1991; p. 807.

41. Delcorte, A.; Bertrand, P. Sputtering of Parent-Like Ions from Large Organic Adsorbates on Metals under keV Ion Bombardment. Surf. Sci. 1998, 412/413, 97-124. 